University of New Hampshire

University of New Hampshire Scholars' Repository

$11-2008$

\title{
Who cares about polar regions? Results from a survey of U.S. public opinion
}

Lawrence C. Hamilton

University of New Hampshire, lawrence.hamilton@unh.edu

Follow this and additional works at: https://scholars.unh.edu/soc_facpub

Part of the Sociology Commons

\section{Recommended Citation}

Hamilton, L.C. Who cares about polar regions? Results from a survey of U.S. public opinion. (2008) Arctic, Antarctic, and Alpine Research, 40 (4), pp. 671-678.

This Article is brought to you for free and open access by the Sociology at University of New Hampshire Scholars' Repository. It has been accepted for inclusion in Sociology Scholarship by an authorized administrator of University of New Hampshire Scholars' Repository. For more information, please contact Scholarly.Communication@unh.edu. 


\section{Who Cares about Polar Regions? Results from a Survey of U.S. Public Opinion}

Source: Arctic, Antarctic, and Alpine Research, 40(4):671-678.

Published By: Institute of Arctic and Alpine Research (INSTAAR), University of Colorado

DOI: http://dx.doi.org/10.1657/1523-0430(07-105)[HAMILTON]2.0.CO;2

URL: http://www.bioone.org/doi/full/10.1657/1523-0430\%2807-105\%29\%5BHAMILTON\%5D2.0.CO $\underline{\% 32}$

BioOne (www.bioone.org) is a nonprofit, online aggregation of core research in the biological, ecological, and environmental sciences. BioOne provides a sustainable online platform for over 170 journals and books published by nonprofit societies, associations, museums, institutions, and presses.

Your use of this PDF, the BioOne Web site, and all posted and associated content indicates your acceptance of BioOne's Terms of Use, available at www.bioone.org/page/terms_of_use.

Usage of BioOne content is strictly limited to personal, educational, and non-commercial use. Commercial inquiries or rights and permissions requests should be directed to the individual publisher as copyright holder. 


\section{Who Cares about Polar Regions? Results from a Survey of U.S. Public Opinion}

\author{
Lawrence C. Hamilton \\ *Sociology Department, University of \\ New Hampshire, Durham, New \\ Hampshire 03824, U.S.A. \\ Larry.Hamilton@unh.edu
}

\begin{abstract}
What do members of the general public know about polar regions, and how much do they care? Who knows or cares? This paper explores data from the General Social Survey (GSS), which in 2006 questioned a representative sample of more than 1800 U.S. adults about their knowledge and opinions concerning polar regions. The polar survey items were modeled on long-running GSS assessments of general science knowledge and opinions, recently summarized in the U.S. National Science Board's report Science and Engineering Indicators 2008. Polar knowledge proves to be limited but certainly not absent among survey respondents. Polar knowledge, general science knowledge, and education - together with individual background characteristics (age, sex, income) - predict policy-relevant opinions. Political orientation filters the impacts of education, and also shows consistent, significant effects across all the polar opinion questions. These 2006 GSS polar results will provide a baseline for comparison when the questions are repeated on a 2010 survey, after the International Polar Year concludes.
\end{abstract}

\section{Introduction}

What do members of the general public know about polar regions, and how much do they care? Who knows or cares? A detailed two-volume report by the U.S. National Science Board, Science and Engineering Indicators 2008 (National Science Board, 2008; hereafter cited as $S E I$ ), addressed similar questions about public attitudes and understanding of science in general. Public attitudes and understanding matter because, as the SEI authors note,

“... science and technology (S\&T) are everywhere. Americans encounter $S \& T$ in their roles as citizens, workers, and consumers. As citizens, they vote for candidates with different views about global warming, stem cell research, and deficit spending, issues about which atmospheric scientists, microbiologists, and macroeconomists claim expertise."

$$
\text { -SEI, p. 7-5 }
$$

Corresponding arguments could be made regarding polar science. Although polar regions are remote from most lowerlatitude residents' experience, these regions have become increasingly prominent in news reports about global climate change. Other trends, including oil and gas development, industrial fisheries, and the expansion of tourism, all have growing impacts on polar environments. Together with climate change, economic interests are focusing new geopolitical attention on these regions. Many scientists claim relevant expertise, and we might hope that their expertise will inform public discussions about polar and climate-related policies.

The SEI report examined general-public attitudes and knowledge as reflected in survey research, primarily from the U.S.A. but also with some international comparisons. The authors focused particularly on the General Social Survey (GSS), a nationally representative personal-interview poll of U.S. adults. The GSS is the largest project funded by the Sociology Program of the U.S. National Science Foundation (NSF). It has been conducted annually or biennially by the National Opinion Research Center (NORC) at the University of Chicago since 1972 (Davis et al., 2007). Each cycle includes a standard core of demographic and attitudinal questions designed to assess social structure and public attitudes, follow changes in these indicators through time, and support research on how they are connected. In addition, each survey contains many topical questions related to specific research interests. Thousands of dissertations, research articles, and books have used the open data from this longrunning series (ICPSR, 2007; NORC, 2007).

Ten GSS surveys over 1985-2006 contained modules of science questions, including a set of mostly true/false items meant to assess "science literacy"-for example, is it true or false that electrons are smaller than atoms? SEI found levels of science literacy to be disappointingly low in absolute terms, although somewhat more encouraging when viewed comparatively against results from other nations or previous years. Science literacy varies with background characteristics such as respondent's age, gender, income and education. Religious beliefs notably affect knowledge in two areas, human evolution and the Big Bang.

In 2006, the GSS included a special set of questions also seeking knowledge and opinions about polar-related topics. These questions were modeled on the general science questions, inviting similarly detailed analysis. With support from the NSF Office of Polar Programs (OPP), the polar module was developed through an iterative process of discussion, review, and pre-testing. Scientists at OPP worked with other researchers from the NSF directorate for Social, Behavioral and Economic Sciences, the Science and Technology Policy Program of SRI International, the Survey Research Center at the University of Michigan, and NORC. The polar module was designed to elicit public understanding and attitudes concerning polar science and policy, on the eve of the International Polar Year (IPY, 2007-2008). Polar questions will be repeated on the GSS in 2010, allowing beforeand after-IPY comparisons. 
TABLE 1

Information and knowledge about polar regions.

"We want to ask about how much information you have on various topics. For each of the following areas, please indicate whether you are very informed, somewhat informed, neither informed nor uniformed, somewhat uninformed, or very uninformed about the issues." (Coded from $0=$ don't know and $1=$ very uninformed to $5=$ very informed. Below are the weighted percentages responding "somewhat informed" or "very informed" on each topic.)

- Foreign policy $(52 \%)$

- Economic policy $(48 \%)$

- Science and technology (59\%)

- Global warming $(59 \%)$

- The North and South Poles (40\%)

"The next few questions are about the Arctic and the Antarctic. The Arctic is the region around the North Pole; Antarctic is the region that contains the South Pole. These questions are like the ones you might see on a television game show. If you don't know or aren't sure, just tell me so, and we will skip to the next question. Remember true, false, or don't know." (Fig. 2 shows responses, and the relation between weighted mean number of correct answer and "North and South Poles information," above.)

- The North Pole is on a sheet of ice that floats on the Arctic Ocean. (41\% true)

- The sun never shines at the South Pole. (67\% false)

- Inuit (often called Eskimos) live north of the Arctic Circle. (44\% true)

- Hunting is more likely than climate change to make polar bears become extinct. (36\% false)

- Would you say the polar ice caps have gotten larger or smaller over the last 25 years? (77\% smaller)

This paper explores the 2006 GSS data on public knowledge or opinions about polar regions. As might be expected from SEI, polar knowledge proves to be limited but certainly not absent among members of the public. Polar knowledge, general science knowledge, and education - together with individual background characteristics such as age, sex, or income - predict policy-relevant opinions. Political orientation, rather than religion (which influenced the $S E I$ items), plays an important role, with significant effects across all polar opinions.

\section{Knowledge about Polar Regions}

GSS selection and contact methods seek to obtain samples that fairly represent the U.S. adult population. After data collection and preliminary analysis, NORC calculates probability weights that allow further adjustments, reducing bias and making survey profiles even closer to the general population (but without altering the number of observations). The 2006 GSS involved 4538 interviews. A random subset of 1863 interviews included the polar questions.

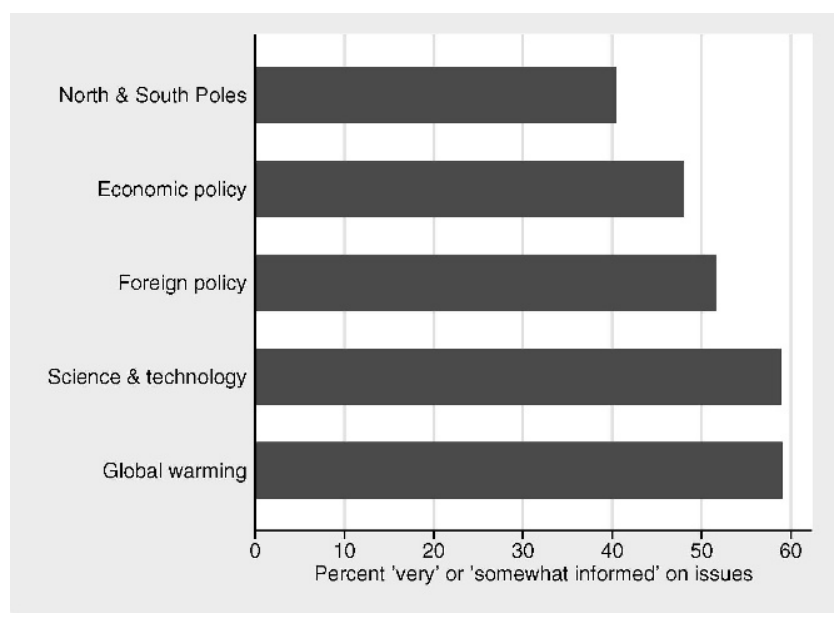

FIGURE 1. Weighted percent of 2006 General Social Survey (GSS) respondents reporting they are "very informed" or "somewhat informed" about polar regions, economic policy, foreign policy, science and technology, or global warming.
The survey assessed respondents' knowledge about polar regions in two ways. One set of questions asked people to selfreport how much information they had on various topics such as foreign policy, economic policy, and the North and South Poles. These questions are listed at top in Table 1, and percentages of respondents saying they are very or somewhat informed on each topic are graphed in Figure 1. Fifty-nine percent described themselves as very or somewhat informed about global warming, and about science and technology. Only 40\%, the lowest among these topics, expressed similar confidence in their information about polar regions. All tables and graphs in this paper employ NORC probability weights. Adjusted confidence intervals for these percentages are within \pm 3 points.

A second set of five questions comprised a simple quiz on polar topics. These questions, such as "The sun never shines at the South Pole. True or false?" are listed at bottom in Table 1. Figure 2 graphs the response distributions. Most people knew that polar ice caps have grown smaller in recent years (77\% answered correctly), and that the sun does sometimes shine at the South Pole (67\%). On the other hand, less than half knew that Inuit live north of the Arctic Circle (44\%), that the North Pole is located on sea ice $(41 \%)$, or that polar bears face less risk from hunting than from climate change (36\%). Correct answers on each of the five individual questions have significant positive correlations with all of the others, with self-assessed levels of polar information, and with $S E I$ science literacy scores, as expected for valid quiz items.

The total number of correct answers on this five-item polar quiz also correlates positively with the $S E I$ science literacy index $(r$ $=+.51)$, and with self-assessed polar information $(r=+.36$; see bottom right graph in Fig. 2). Respondents who described themselves as "very uninformed" about polar topics answered about 2 out of 5 questions correctly, on average. Those describing themselves as "very informed" performed better, but even so averaged only 3.3 correct answers. Thus, although self-reported levels of polar information are lower than for other topics, we might view them as overstating factual knowledge.

\section{Opinions on Polar Issues}

Another set of GSS questions sought opinions on polarrelated issues. These questions are listed in Table 2. Five questions asked how concerned people were about some possible conse- 

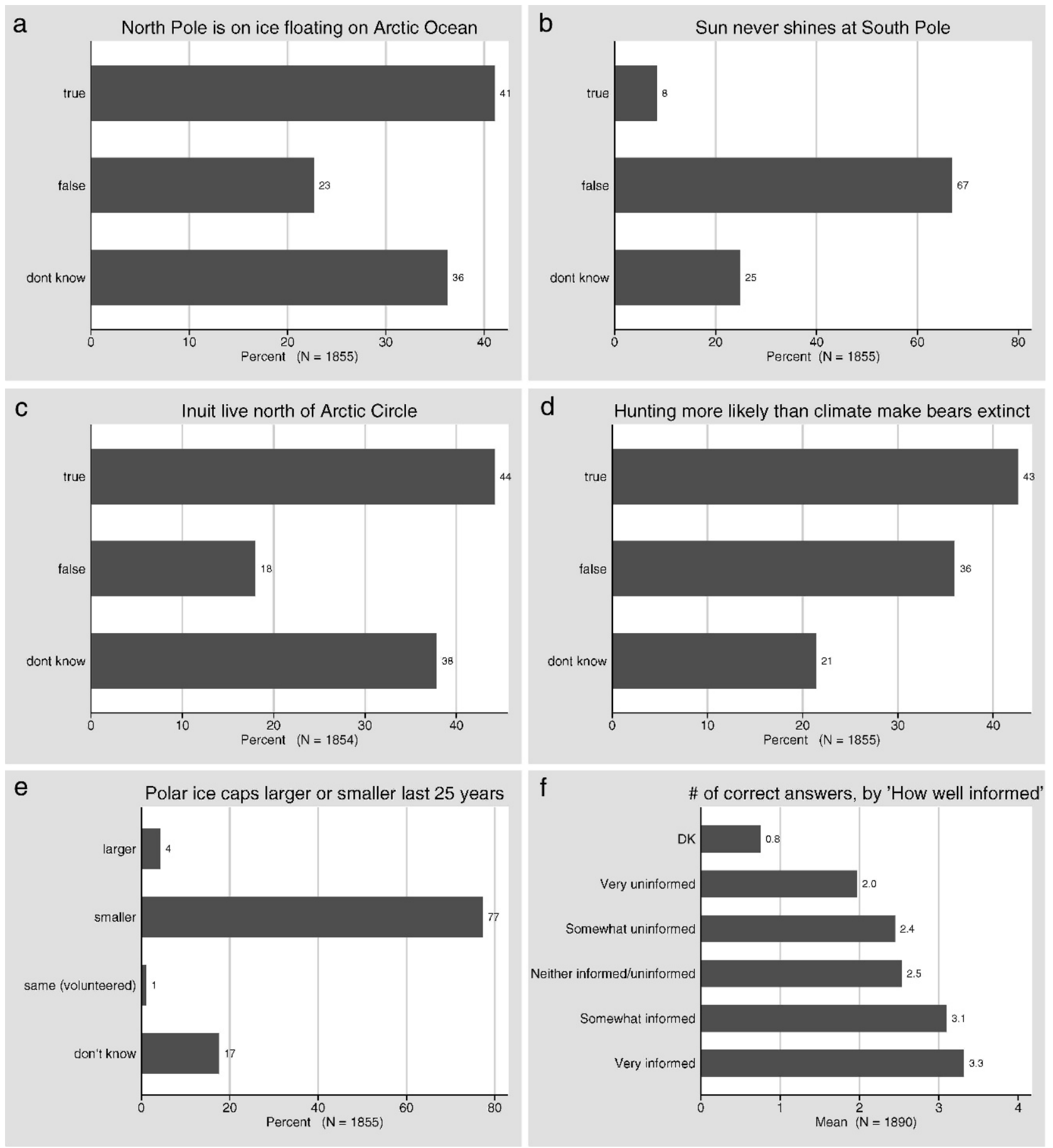

FIGURE 2. Weighted responses on five polar-knowledge questions from the $2006 \mathrm{GSS}$, and (lower right) average knowledge score by selfassessed level of information $(r=+.36)$.

quences of climate warming in the polar regions. Figure 3 shows the distributions of responses. Most people said they would be bothered a great deal if sea levels rose 20 feet, flooding coastal areas $(70 \%)$, or if the northern ice cap completely melted (63\%). It seems likely that many respondents connected the ice melting with sea-level rise, and considered these to be almost the same question-although Arctic Ocean sea ice (as distinct from the Greenland Ice Sheet) could melt completely without much affecting sea levels.

Public concern about Inuit losing their traditional way of life ( $45 \%$ bothered a great deal), extinction of polar bears $(45 \%)$, or threatened Arctic seals (43\%) all ranked lower than sea-level rise.
Although the Inuit and Arctic wildlife are distant issues for most people, only small minorities said they would be bothered a little, or not at all.

A sixth opinion question asked whether respondents believed that Antarctica should be reserved primarily for science, or opened for commercial purposes. A plurality of respondents (46\%) strongly or somewhat supported reserving the Antarctic for science. Many were neutral or didn't know on this issue $(35 \%)$. Relatively few (19\%) strongly or somewhat supported opening the Antarctic for commercial purposes.

In the next section we examine patterns in who supports reserving the Antarctic, or expresses more concern about polar 


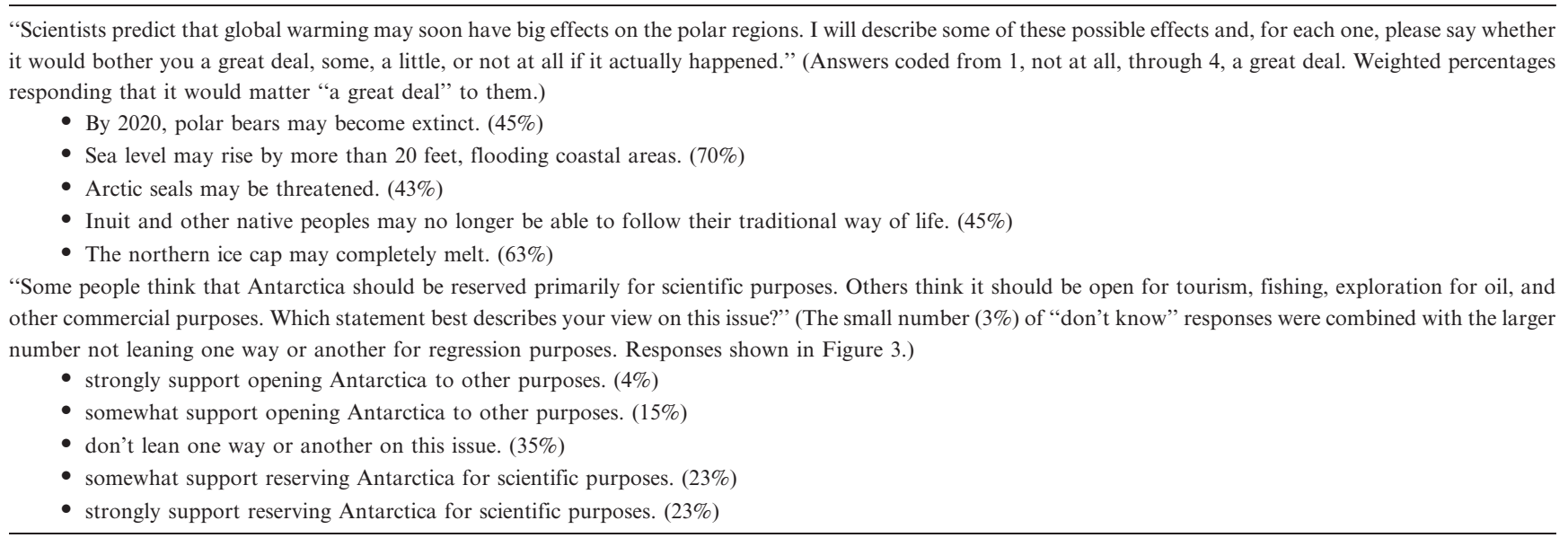

aspects of climate warming. These views vary with individual background, politics, and knowledge.

\section{Who Cares about Polar Regions?}

The SEI authors observe that factual knowledge of science is positively related to education, income, and number of science and math courses; negatively related to age; and, outside the biological sciences, tends to be higher among men than women (p. 7-18). These patterns extend even to science topics (such as nanotechnology or polar change) that are too new for most respondents to have learned about them in school (p. 7-19). Moreover, the patterns in science knowledge closely parallel those for general civic knowledge. Controlling for background characteristics such as age, sex, and education, people with greater science knowledge tend to hold more favorable views towards science in general, and this relationship strengthens for specific domains where they are knowledgeable (Allum et al. 2008)

Approaching related questions from a different angle, environmental sociologists have developed a body of knowledge about "the social bases of environmental concern"-social characteristics associated with higher expressions of concern about environmental problems (e.g., Van Liere and Dunlap, 1980; Jones and Dunlap, 1992; Davidson and Freudenburg, 1996; Carman, 1998; Dietz et al., 2005, 2007; Xiao and McCright, 2007). Such research asks literally, Who cares about the environment? Concern about the environment has been found to be higher among young adults, people with college educations, and those holding liberal rather than conservative political views. On certain environmental topics, women express greater concern than men. Research on the social bases of concern about climate change, in particular, has looked closely at the roles of education and knowledge, including how these are filtered by ideology or preexisting beliefs (e.g., Krosnick et al., 2006; Leiserowitz, 2004, 2006; Lorenzoni and Pidgeon, 2006; Nisbet, 2005; Pew, 2006, 2007; Wood and Vedlitz, 2007). Environmental concern often has connections to both science and political discourse. Those connections are particularly salient in the case of climate change.

Multiple regression-type statistical models, which estimate the net effects of several competing predictors on one dependent variable, have been used widely both for science-indicators and environmental-concern research. Ordered-category dependent variables, such as the GSS polar opinion questions, can be approached through a technique called ordered logit regression (1). Such models allow us to explore how polar opinions are related to the usual background characteristics and, net of background effects, what are the impacts of science knowledge.

Table 3 summarizes results from weighted regressions of six polar concern or opinion questions (defined in Table 2; responses shown in Fig. 3) on respondent background characteristics and scientific knowledge. The background variables (with weighted percentages or means for the polar subset of GSS) are as follows:

- age in years (18 to 89 , mean 45.3$)$;

- gender (coded $0=$ male or 1 = female, $56 \%$ female);

- family income $($ coded $1=$ under $\$ 1,000$ to $25=\$ 150,000$ or more, mean 17.6; the median is about $\$ 40,000$ );

- highest degree earned (from $1=$ high school to $4=$ postgraduate, mean 1.9);

- conservative, respondent's political identification (from $1=$ extremely liberal to $7=$ extremely conservative, mean 4.2 ); and

- conservative $\times$ degree (interaction term defined as the product of conservative times degree).

To reduce problems of multicollinearity, degree and conservative were centered (expressed as deviations from their unweighted means) before calculating the interaction term conservative $\times$ degree, and including all three in the models.

In addition to these background variables, we also considered five indicators of general or polar science knowledge as possible predictors:

- high school science, number of science subjects taken in high school (from 0 to 3 , mean 1.7);

- college major, natural-science college degree $(\operatorname{coded} 0=$ no or $1=$ yes, $11 \%$ yes);

- well informed, self-assessed level of information about polar regions (from $0=$ don't know to $5=$ very informed, mean $3)$;

- polar quiz, number of correct answers to five polarknowledge questions seen in Table 1 and Figure 2 (from 0 to 5 , mean 2.7);

- science literacy, number of correct answers to 11 non-polar science knowledge questions described on p. 7-17 of SEI (from 0 to 11, mean 6.5). 

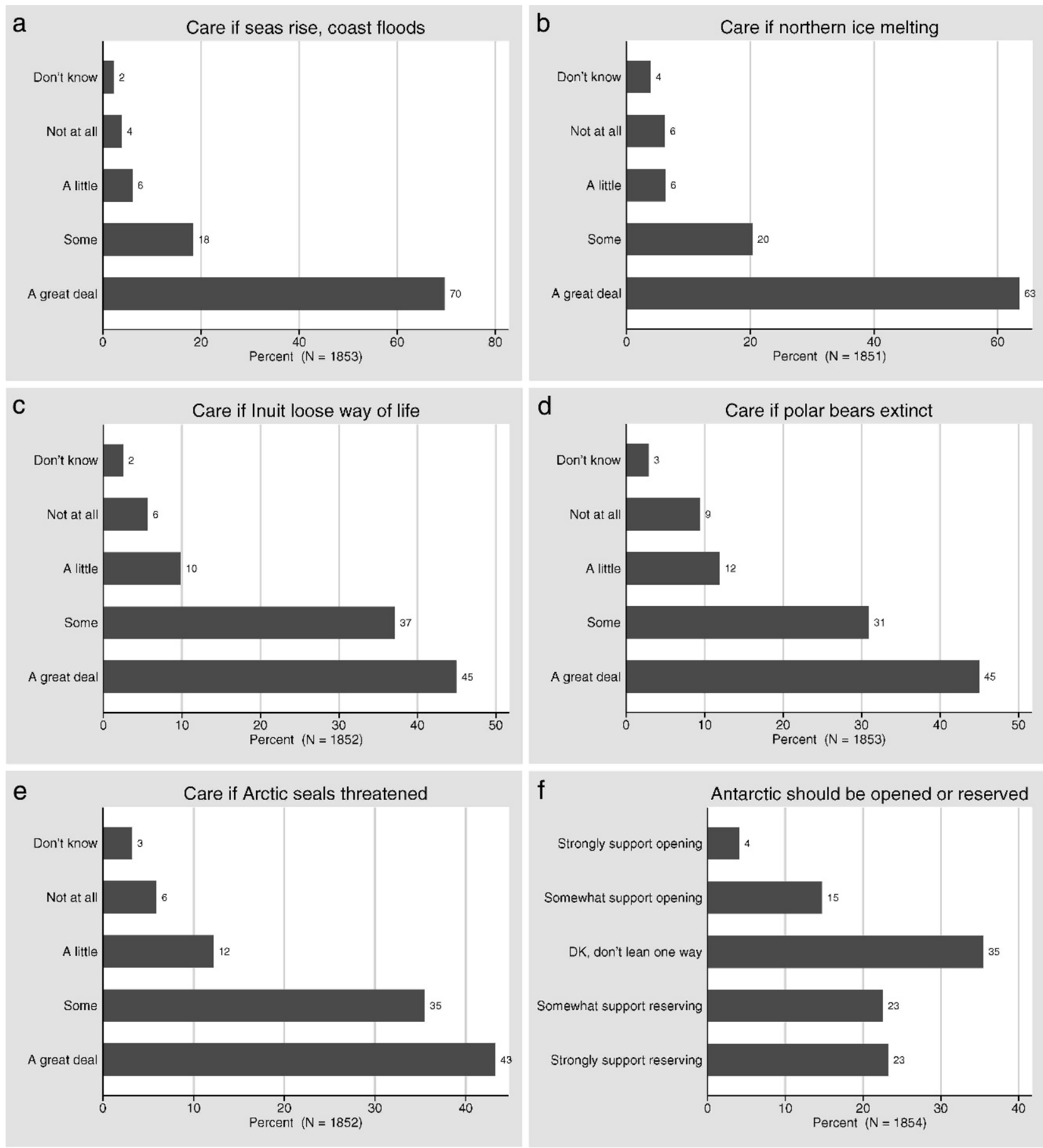

FIGURE 3. Degree of concern on five polar results of global warming, and (lower right) views on reserving the Antarctic for research vs. opening it for economic purposes.

The coefficients in Table 3 are estimates of $\beta$ coefficients in models of the form

$$
\begin{aligned}
S_{i}= & \beta_{1} \text { age }_{i}+\beta_{2} \text { gender }_{i}+\beta_{3} \text { income }_{i}+\beta_{4} \text { degree }_{i} \\
& +\beta_{5} \text { conservative }_{i}+\beta_{6}{\text { conservative } \times \text { degree }_{i}} \\
& +\beta_{7} \text { highschool }_{i}+\beta_{8} \text { major }_{i}+\beta_{9} \text { informed }_{i} \\
& +\beta_{10} \text { polarquiz }_{i}+\beta_{11} \text { scilit }_{i}
\end{aligned}
$$

where $S_{i}$ is the ordered-logit score for the $i$ th individual, as described in note (1) following the text. Asterisks in Table 3 denote statistically significant effects. Thus, age shows a significant negative effect (net of all other predictors) on concern about sea level rise, income shows a significant positive net effect, and so forth.

Earlier studies have found that both science knowledge and environmental concern tend to be higher among younger respondents. Age had little impact on most of our polar issues, however. Only responses to the sea-level question exhibit a significant age effect. The odds of high concern about sea-level rise decline slightly with each year of age, as indicated by the negative logit coefficient $\left(\beta_{1}=-.01, p<.05\right)$. The age effect, as with all others described in this section, should be understood as a net effect - the estimated impact of variations in age alone, among people identical on all 10 other predictors. 
TABLE 3

Degree of concern about five polar results of global warming, and views on reserving the Antarctic (dependent variables seen in Table 2 and Fig. 3), predicted from respondent background characteristics (including the interaction of ideology and education), and indicators of science knowledge. Coefficients and tests are from probability-weighted ordered logit regression models. Figure 4 interprets the conserve $\times$ degree interaction effect for sea level.

\begin{tabular}{|c|c|c|c|c|c|c|}
\hline \multirow[b]{2}{*}{ Independent variables } & \multicolumn{6}{|c|}{ Dependent variables } \\
\hline & Sea level & Melting ice caps & Inuit life & Bears extinct & Seals threatened & Antarctica reserved \\
\hline \multicolumn{7}{|l|}{ Background } \\
\hline Age in years & $-.01 * *$ & .00 & .00 & -.00 & .00 & -.00 \\
\hline Female & .24 & .27 & $.75^{* *}$ & $.40^{* *}$ & $.65^{* *}$ & .22 \\
\hline Income & $.04 * *$ & $.03 *$ & .02 & .02 & .02 & .01 \\
\hline Highest degree & $.24^{* *}$ & .10 & .01 & .07 & -.01 & .01 \\
\hline Conservative & $-.15^{* *}$ & $-.20 * *$ & $-.15^{* *}$ & $-.14^{* *}$ & $.18^{* *}$ & $-.19^{* *}$ \\
\hline Conserv $\times$ degree & $-.13^{* *}$ & $-.10^{*}$ & -.06 & $-.11 * *$ & $-.12 * *$ & -.05 \\
\hline \multicolumn{7}{|l|}{ Science } \\
\hline$\overline{\text { High school }}$ & -.05 & -.01 & .01 & -.01 & .00 & .10 \\
\hline College major & $-.48 *$ & -.40 & -.34 & -.22 & $-.48^{*}$ & -.04 \\
\hline Well informed & .09 & $.22 * *$ & $.12 *$ & .10 & $.14^{*}$ & -.01 \\
\hline Polar quiz & .10 & $.19^{* *}$ & .05 & $.25^{* *}$ & $.18^{* *}$ & $.22 * *$ \\
\hline Science literacy & .07 & $.14^{* *}$ & .01 & $.10^{* *}$ & $.10^{* *}$ & .05 \\
\hline \multicolumn{7}{|l|}{ Ologit cut points } \\
\hline$\overline{\text { Cut1 }}$ & -3.44 & -1.00 & -3.33 & -2.12 & -2.22 & -2.01 \\
\hline Cut2 & -2.09 & .24 & -1.63 & -.20 & -.68 & -.07 \\
\hline Cut3 & -1.10 & .86 & -.45 & .86 & .71 & 1.46 \\
\hline Cut4 & .17 & 2.17 & 1.47 & 2.43 & 2.52 & 2.64 \\
\hline
\end{tabular}

* Coefficient statistically significant at $\alpha=.05$.

** Coefficient statistically significant at $\alpha=.01$.

Gender, too, has often been linked to knowledge and opinions. On certain environmental issues, women tend to express higher levels of concern. Three of our polar issues follow that pattern: concern about Inuit losing their traditional way of life, polar bears becoming extinct, or Arctic seals being threatened. Regarding the less compassionate topics of sea level, ice melt, or Antarctica, we see no significant gender effects. Income shows an opposite pattern-respondents with higher family incomes (but otherwise the same) express more concern about sea level rise or ice caps melting, which have major economic dimensions, but not about the Inuit, bears, or seals.

Environmental concern typically rises with the level of respondents' education, and declines with a more conservative

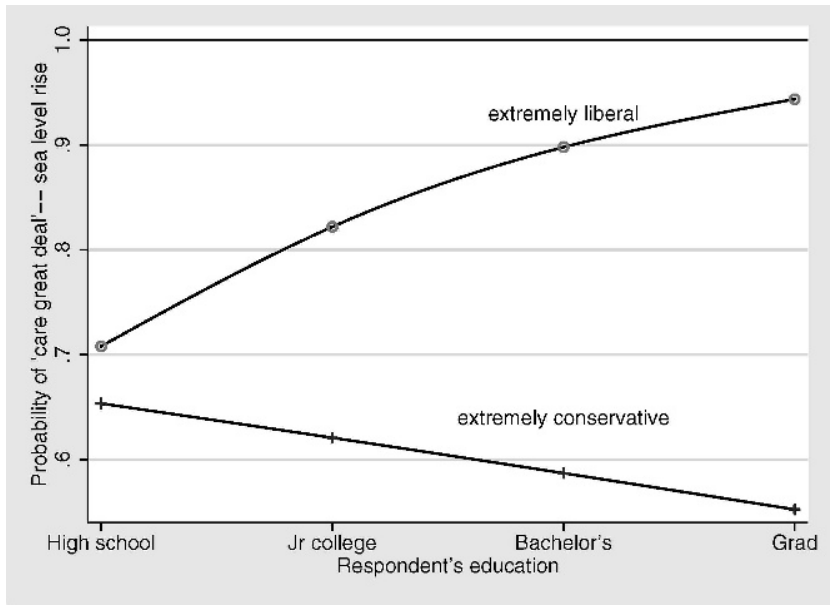

FIGURE 4. Probability that respondents say it would "matter a great deal" to them if sea level rose 20 feet vs. education-for the most liberal and conservative respondents (calculated from the lefthand model in Table 3, with other variables set at means). ideology (McCright and Dunlap, 2000; Dietz et al., 2005, 2007). Consequently, respondent's highest earned degree, and selfidentification on a liberal-to-conservative scale, were included among the predictors. Highest degree positively affects concern about sea-level rise, although not other measures - but note that this limited impact occurs net of the effects of five more specific science-knowledge indicators. Conservative ideology, on the other hand, has highly significant negative effects on all five measures of climate-change concern, and also on reserving the Antarctic for science.

Some research has suggested that, particularly with respect to global warming, education and ideology effects are not simply additive. For example, a Pew Research Center study reported that "Among Republicans, higher education is linked to greater skepticism about global warming .... But among Democrats, the pattern is the reverse ..." (Pew, 2007, p. 2; also see Nisbet, 2005; Krosnick et al., 2006). Wood and Vedlitz (2007) propose a theoretical model based on information processing, noting that "... people process information about issues through a filter containing a range of variables relating to their predispositions ..." (p. 556). New information or knowledge about climate change might overcome predispositions in time, but the Pew (2007) and Nisbet (2005) studies, among others, suggest that this has not happened yet for climate change. To test the hypothesis that education might have different effects, depending upon predispositions, the models in Table 3 include interaction terms defined as the product conservative $\times$ degree.

For four of the six dependent variables, this interaction effect is negative and statistically significant. Concern about polar aspects of global warming thus increase with education among respondents who describe themselves as liberal or moderate, but decrease with education among conservatives (Fig. 4). The ideology-education interaction effects are not significant for two other dependent variables, the Inuit way of life or reserving the 
Antarctic, but even there they have the hypothesized negative signs. More complicated models that also allowed interactions between ideology and general science education or specifically polar knowledge (conservative $\times$ high school science, conservative $\times$ college major, conservative $\times$ well informed, and conservative $\times$ polar quiz) were tested, but unlike conservative $\times$ degree, those terms seemed to have little net effect.

The number of high school science subjects had no net effect on any dependent variable. Unexpectedly, respondents with college degrees in natural science expressed significantly lower levels of concern about sea level rise and Arctic seals, perhaps in part because the broad category of "natural science" degrees includes subjects with no connection to polar or climate topics (see note 2). Because these are net effects, they estimate the statistical impact of being a science major (or not) if we compared groups of people otherwise identical in education, general science and polar knowledge, politics, and background characteristics. Feeling wellinformed about polar topics and scoring well on the polar or science literacy quizzes generally did have the expected association with higher levels of concern or support for Antarctic science.

\section{Discussion}

From an $S E I$-informed perspective, the lack of science knowledge evident in Figures 1 and 2 is not surprising. Results in Figure 3 do provide some encouragement for polar sciencelarge majorities of respondents express at least some concern about the polar consequences of climate change, even those with no direct impacts on mid-latitude life. Levels of concern are highest regarding the apparent risks of sea-level rise and coastal flooding (70\% would be bothered "a great deal") or polar ice melting (63\%). Somewhat fewer would, more altruistically, be bothered a great deal by threats to the Inuit way of life $(45 \%)$, polar bears $(45 \%)$, or seals $(43 \%)$.

Better knowledge would evidently be helpful. People who feel better informed about polar issues, or answered more questions correctly, also tend to express greater concern regarding climatechange consequences, and to favor reserving Antarctica for science. To the extent that public education follows from IPY, we might hope to detect higher levels of information and knowledge on surveys in subsequent years. The rising volume of media reports about polar environmental, economic, social, and geopolitical developments should contribute to public awareness as well.

From a social science perspective, the results in Table 3 are notable for their consistency with non-polar research about the social bases of environmental concern in general, and climate change in particular. Surveys of public opinion often find that concern about the environment is higher among young, female, or well-educated respondents, and lower among those self-identified as conservative. These polar results also, for the most part, agree with the meta-analysis findings of Allum et al. (2008) that, after controlling for background factors, greater science knowledge is associated with higher opinions of scientists and research. Scores on the domain-specific GSS polar knowledge quiz, for example, had their strongest effects in predicting opinions about reserving the Antarctic for science.

The interaction between ideology and education (Fig. 4) adds an interesting dimension, consistent with polling results (e.g., Pew, 2007) and the information-processing perspective of Wood and Vedlitz (2007), but not previously observed with respect to polar topics. This finding suggests that ideology can be a powerful filter. More educated people have greater confidence that they understand climate-change science, and that this science supports their political predispositions. Public debates about climate change provide anecdotal evidence for such a process, but here we find it at work in a large-sample survey, and even after adjusting for the influence of age, gender, income and five other knowledge indicators.

Finally, the modeling results in Table 3 open another dimension of possible comparisons when post-IPY results become available from the 2010 GSS. We then can explore not only how polar awareness has changed, but for whom - whether broadly or among identifiable subsets of the population. Will there be shifts in how we answer the question, Who cares? Will polar and climate opinions become less politically aligned over time, in the wake of IPY and other new research?

\section{Notes}

(1) Ordered logit models estimate a score for the $i$ th observation $\left(S_{i}\right)$ as a linear function of values on one or more predictors $\left(x_{i}^{\prime} \mathrm{s}\right)$ :

$$
S_{i}=\beta_{1} x_{1 i}+\beta_{2} x_{2 i}+\ldots+\beta_{m} x_{m i}
$$

Predicted probabilities for the ordered categories of outcome $y$ depend on the value of $S$ plus a logistically distributed disturbance $u$, relative to estimated cut points. The GSS questions regarding polar consequences of global warming, for example, allow five possible answers. To evaluate how the probability of each answer varies with respondent characteristics, we estimate $\beta$ parameters representing the effect of each characteristic, along with four cut points such that

- $\operatorname{Pr}\left(y_{i}=\right.$ "don't know") $=\operatorname{Pr}\left(S_{i}+u_{i} \leq\right.$ cut 1$)$,

- $\operatorname{Pr}\left(y_{i}=\right.$ "not at all") $=\operatorname{Pr}\left(\right.$ cut1 $<S_{i}+u_{i} \leq$ cut2 $)$,

- $\operatorname{Pr}\left(y_{i}=\right.$ "a little") $=\operatorname{Pr}\left(\right.$ cut2 $<S_{i}+u_{i} \leq$ cut3 $)$,

- $\operatorname{Pr}\left(y_{i}=\right.$ "some") $=\operatorname{Pr}\left(\right.$ cut3 $<S_{i}+u_{i} \leq$ cut 4$)$,

- $\operatorname{Pr}\left(y_{i}=\right.$ "a great deal") $=\operatorname{Pr}\left(\right.$ cut4 $\left.<S_{i}+u_{i}\right)$.

These probabilities are non-linear (logit) functions of the cut points and $S_{i}$. Separate analyses confirmed that "don't know" responses could most realistically be viewed as very low levels of concern, but the general results are similar even if don't-knows are set aside. For more details on logit modeling, see Long (1997), Hosmer and Lemeshow (2000), or Long and Freese (2006). Hamilton (2009) describes conditional effect plots such as Figure 4.

(2) Following SEI (p. 2-10), "natural science" was defined broadly to include degrees in agricultural, biological, health, physical, earth, atmospheric, and ocean sciences; mathematics; and computer sciences. A narrower definition might seem theoretically appealing, but would leave too few observations for analysis. For example, the 2006 GSS included only 23 people with college degrees in biology, 4 in chemistry, and 3 in geology. Even under the broadest definition, just $11 \%$ of the sample held naturalscience degrees.

\section{Acknowledgments}

Researchers at NSF, NORC, SRI, and the University of Michigan conceived and implemented the polar module for the 2006 General Social Survey. Without their efforts, there would be nothing here to report. Anna Kerttula de Echave (NSF Arctic Social Sciences) and Robert Bell (NSF Science Resources Statistics) provided information and helpful suggestions for an earlier draft. The final paper benefitted from reviewers' suggestions. 


\section{References Cited}

Allum, N., Sturgis, P., Tabourazi, D., and Brunton-Smith, I., 2008: Science knowledge and attitudes across cultures: A metaanalysis. Public Understanding of Science, 17(1): 35-54.

Carman, C., 1998: Dimensions of environmental policy support in the United States. Social Science Quarterly, 79: 717-733.

Davidson, D. J., and Freudenburg, W. R., 1996: Gender and environmental risk concerns: a review and analysis of available research. Environment and Behavior, 28: 302-339.

Davis, J. A., Smith, T. W., and Marsden, P. V., 2007: General Social Surveys, 1972-2006 [CUMULATIVE FILE] [Computer file]: ICPSR04697-v2. Chicago, Illinois: National Opinion Research Center [producer], 2007. Storrs, Connecticut: Roper Center for Public Opinion Research, University of Connecticut/ Ann Arbor, Michigan: Inter-University Consortium for Political and Social Research [distributors], 2007-09-10.

Dietz, T., Fitzgerald, A., and Shwom, R., 2005: Environmental values. Annual Review of Environment and Resources, 30: 335-374.

Dietz, T., Dan, A., and Shwom, R., 2007: Support for climate change policy: social psychological and social structural influences. Rural Sociology, 72: 185-214.

Hamilton, L. C., 2009: Statistics with Stata, version 10. Belmont, California: Cengage.

Hosmer, D. W., and Lemeshow, S., 2000: Applied Logistic Regression. New York: Wiley.

ICPSR, 2007: General Social Survey Series. Ann Arbor, Michigan, Inter-University Consortium for Political and Social Research (http://www.icpsr.umich.edu/cocoon/ICPSR/SERIES/ 00028.xml accessed on 9 December 2007).

Jones, R. E., and Dunlap, R. E., 1992: The social bases of environmental concern: have they changed over time? Rural Sociology, 57: 28-47.

Krosnick, J. A., Holbrook, A. L., Lowe, L., and Visser, P. S., 2006: The origins and consequences of democratic citizens' policy agendas: a study of popular concern about global warming. Climatic Change. doi: 10.1007/s10584-006-9068-S.

Leiserowitz, A. A., 2004: Before and after the day after tomorrow: a US study of climate change risk perception. Environment, 46(9): 22-37.

Leiserowitz, A. A., 2006: Climate change risk perception and policy preferences: the role of affect, imagery and values. Climatic Change, 77: 45-72.
Long, J. S., 1997: Regression Models for Categorical and Limited Dependent Variables. Thousand Oaks, California: Sage.

Long, J. S., and Freese, J., 2006: Regression Models for Categorical Dependent Variables Using Stata. 2nd edition. College Station, Texas: Stata Press.

Lorenzoni, I., and Pidgeon, N. F., 2006: Public views on climate change: European and USA perspectives. Climatic Change, 77(1-2): 73-95.

McCright, A. M., and Dunlap, R. E., 2000: Challenging global warming as a problem: an analysis of the conservative movement's counter-claims. Social Problems, 50(3): 348-373.

National Science Board, 2008: Science and Engineering Indicators 2008. Two volumes. Arlington, Virginia: National Science Foundation (volume 1, NSB 08-01; volume 2, NSB 08-01A).

Nisbet, M. C., 2005: The multiple meanings of public understanding: why definitions matter to the communication of science. Committee for Skeptical Inquiry (http://www.csicop. org/scienceandmedia/definitions/ accessed 15 December 2007).

NORC, 2007: General Social Survey. National Opinion Research Center (http://www.norc.org/projects/General+Social+Survey. htm accessed on 9 December 2007).

Pew, 2006: Little consensus on global warming: partisanship drives opinion (http://people-press.org/reports/display. php3?ReportID $=280$ accessed on 17 November 2007).

Pew, 2007: Global warming: a divide on causes and solutions. Pew Research Center, January 24. (http://people-press.org/reports/ pdf/303.pdf accessed on 14 December 2007).

Van Liere, K. D., and Dunlap, R. E., 1980: The social bases of environmental concern: A review of hypotheses, explanations and empirical evidence. Public Opinion Quarterly, 44(2): 181-197.

Wood, B. D., and Vedlitz, A., 2007: Issue definition, information processing, and the politics of global warming. American Journal of Political Science, 51(3): 552-568.

Xiao, C., and McCright, A. M., 2007: Environmental concern and sociodemographic variables: a study of statistical models. Journal of Environmental Education, 38: 3-13. 